\title{
Dyslipidaemia pattern and prevalence among type 2 diabetes mellitus patients on lipid-lowering therapy at a tertiary hospital in central South Africa
}

\author{
Lebohang Pitso ${ }^{1,2^{*}}$, Thabiso Rafaki Petrus Mofokeng ${ }^{3}$ and Riette Nel ${ }^{4}$
}

\begin{abstract}
Background: Atherosclerotic cardiovascular disease (ASCVD) is a major cause of death worldwide. A large number of deaths due to ASCVD occurs among people with diabetes mellitus (DM). One of the important modifiable risk factors associated with ASCVD is dyslipidaemia and its prevalence is not known in central South Africa (SA). This study aimed to determine the pattern and prevalence of dyslipidaemia among type 2 diabetes mellitus (T2DM) patients on lipid-lowering therapy.

Methods: This descriptive, retrospective study of patients' records was conducted at Universitas Academic Hospital in Bloemfontein, SA. The study population included 143 consecutive T2DM patients of any age that attended the Diabetes Clinic from 1 January to 31 March 2019. The patients had to be on lipid-lowering therapy for a minimum duration of 3 months. Data were sourced from the clinic files and included the patient's lipid profile, anthropometric and demographic data. Dyslipidaemia was defined using the 2018 SA dyslipidaemia guidelines.

Results: The median age of the participants was 63 years (interquartile range [IQR] 52-71 years). The majority of the participants were female $(n=92 ; 64.3 \%)$. The median duration since the DM diagnosis was 18 years (IQR 13-23 years). The prevalence of dyslipidaemia was $86.7 \%(n=124)$. Combined dyslipidaemia, namely either triglycerides (TG) + low-density lipoprotein cholesterol (LDL), high-density lipoprotein cholesterol (HDL) + TG or HDL + LDL, was the most common pattern $(n=51 ; 42.5 \%)$ largely due to raised TG + LDL contributing $37.2 \%(n=19)$ to this pattern. The second and third most common patterns were isolated (either $L D L, H D L$ or TG) and mixed dyslipidaemia $(\mathrm{TG}+\mathrm{HDL}+\mathrm{LDL})$ at $40.8 \%(n=49)$ and $16.7 \%(n=20)$, respectively. The most frequent lipid abnormality $(n=84 ; 70.0 \%$ ) was LDL of $\geq 1.8 \mathrm{mmol} / \mathrm{L}$. Of the 140 participants on statin therapy, only $5 \%$ were on high-intensity therapy.
\end{abstract}

\footnotetext{
* Correspondence: PitsoL@ufs.ac.za

'Division of Endocrinology, Department of Internal Medicine, Faculty of Health Sciences, University of the Free State, Universitas Academic Hospital, Bloemfontein, South Africa

2Department of Internal Medicine, Faculty of Health Sciences, University of the Free State, 205 Nelson Mandela Drive, 9300 Bloemfontein, South Africa Full list of author information is available at the end of the article
}

C The Author(s). 2021 Open Access This article is licensed under a Creative Commons Attribution 4.0 International License, which permits use, sharing, adaptation, distribution and reproduction in any medium or format, as long as you give appropriate credit to the original author(s) and the source, provide a link to the Creative Commons licence, and indicate if changes were made. The images or other third party material in this article are included in the article's Creative Commons licence, unless indicated otherwise in a credit line to the material. If material is not included in the article's Creative Commons licence and your intended use is not permitted by statutory regulation or exceeds the permitted use, you will need to obtain permission directly from the copyright holder. To view a copy of this licence, visit http://creativecommons.org/licenses/by/4.0/. The Creative Commons Public Domain Dedication waiver (http://creativecommons.org/publicdomain/zero/1.0/) applies to the data made available in this article, unless otherwise stated in a credit line to the data. 
Conclusions: A high prevalence of dyslipidaemia among DM patients was observed, despite the use of lipidlowering therapy in this small observational study. Our findings highlight the need to better educate healthcare providers regarding the intensification of lipid-lowering therapy, along with improved strategies to address poor glycaemic control and other modifiable lifestyle factors.

Keywords: Atherosclerotic cardiovascular disease, ASCVD, Type 2 diabetes mellitus, T2DM, Dyslipidaemia, Lipidlowering therapy, Low-density lipoprotein cholesterol, LDL-C, Statin

\section{Background}

Diabetes mellitus (DM) is on the increase globally and most alarmingly in the Africa region. An estimated 463 million of the global adult population were living with DM in 2019, and the global prevalence has doubled to $9.3 \%$ since 2000 . The Africa region has the highest proportion in the world of both undiagnosed DM (59.7\%) and DM-related deaths occurring under 60 years of age (73.1\%). Atherosclerotic cardiovascular disease (ASCVD) is the largest contributor to both morbidity and mortality for people with DM, with the relative risk of ASCVD between 1.6 and 2.6 [1].

Dyslipidaemia associated with DM is an important modifiable metabolic risk factor to reduce ASCVD [1]. Diabetic dyslipidaemia, also known as atherogenic lipoprotein phenotype (ALP) or atherogenic dyslipidaemia, manifests with elevated fasting and postprandial triglycerides (TG), low high-density lipoprotein cholesterol (HDL-C) and normal to mildly elevated low-density lipoprotein cholesterol (LDL-C) with the predominance of atherogenic small dense low-density lipoprotein (sdLDL) particles [2-4]. This pattern is mainly due to hepatic overproduction of TG-rich very-low-density lipoprotein (VLDL) particles and accelerated exchange of TG in VLDL for cholesteryl esters in HDL and LDL producing sdLDL $[2,3,5]$.

Elevated LDL-C, a form of dyslipidaemia, as the cause of ASCVD is unequivocal [6, 7]. Coronary artery disease (CAD), ischaemic stroke and peripheral vascular disease (PVD) are all increased two- to four-fold in the DM population, while heart failure risk is even greater with the risk reported as high as eight-fold in some studies [8-11].

Lowering cholesterol levels, among other metabolic risk factors, can significantly reduce the risk of ASCVD outcomes [1]. Statin therapies have been shown to significantly reduce ASCVD events, including in people with type 2 diabetes mellitus (T2DM) [4, 12, 13]. Among the DM population, cardiovascular (CV) benefits with the use of statins are seen for both primary and secondary prevention $[14,15]$. The 5-year incidence of major cardiovascular disease (CVD) events is reduced by $23 \%$ for every $1 \mathrm{mmol} / \mathrm{L}$ reduction in LDL-C [4]. As a result, statin therapy is recommended as a first-line treatment for primary and secondary prevention of ASCVD by major society guidelines $[4,16]$.
Ezetimibe, a non-statin therapy, has been proven to result in additional lowering of LDL-C levels when added to statin therapy and significantly reduced primary composite CV endpoint [17]. Approximately $27 \%$ of this study population had the diagnosis of DM [17].

Both the South African (SA) dyslipidaemia and T2DM guidelines classify $\mathrm{T} 2 \mathrm{DM}$ as a high $\mathrm{CV}$ risk condition and $\mathrm{CV}$ risk scoring is not needed to initiate statin therapy for primary CVD prevention [18, 19]. Based on these guidelines, most T2DM patients' recommended LDL-C target is $<1.8 \mathrm{mmol} / \mathrm{L}$. Other recommended lipid targets are $\mathrm{TG}<1.7 \mathrm{mmol} / \mathrm{L}$, HDL-C of $>1.2 \mathrm{mmol} / \mathrm{L}$ in women and $>1.0 \mathrm{mmol} / \mathrm{L}$ in men $[18,19]$.

Despite the higher risk of ASCVD associated with an abnormal lipid profile, dyslipidaemia is undertreated. In one multi-centre study of over 7000 participants in Europe, only $45 \%$ of the participants with atherogenic dyslipidaemia were on lipid-lowering therapy [20]. In another SA study that evaluated the achievement of LDL-C targets in patients on lipid-lowering therapy in clinical practice, only $41.4 \%$ of patients achieved their LDL-C target [21]. In the European study, approximately $27 \%$ [20] and in the SA study $64 \%$ [21] of the participants had T2DM. A previous report assessing lipid goal attainment in patients on lipid-lowering therapy in central SA was done in the private sector and included patients with and without DM [21].

In our setting, there is a lack of data regarding the prevalence and pattern of dyslipidaemia among T2DM patients on lipid-lowering therapy. Additionally, data regarding the attainability of lipid targets using lipidlowering therapy are not available. Therefore, this study aimed to determine the pattern and prevalence of dyslipidaemia among T2DM patients on lipid-lowering therapy attending a public sector tertiary Diabetes Clinic in the Free State province of SA. Also, the attainability of the LDL-C treatment target amongst other lipid level targets was investigated.

\section{Methods}

Study design and setting

A retrospective study was conducted based on the records of T2DM patients that visited Universitas Academic Hospital Diabetes Clinic, Free State Province, 
from 1 to 2019 to 31 March 2019. The Diabetes Clinic is based in the public sector and provides tertiary care service to a majority of the 2.9 million inhabitants of the province.

\section{Inclusion and exclusion criteria}

Records of all T2DM patients of any age who had been consulted during the relevant period and were on a minimum of 3 months' lipid-lowering therapy were enrolled in the study. Patients with type 1 DM (T1DM), gestational diabetes or secondary causes of diabetes, and patients not on lipid-lowering therapy for a minimum period of 3 months, were excluded from the study. Patient records with incomplete information were also excluded.

\section{Population and sampling}

The files were sourced based on the clinic's diary that keeps a record of all the consultation visits. On average, this referral clinic conducts 960 consultations per year and the majority of the patients are seen at least every six months and most have T2DM. Consecutive sampling was used and a total of 257 patient records were screened during the 3-month study period. The clinical data that were obtained from the patient records included age, gender, ethnicity, T2DM duration, presence or absence of ischaemic heart disease, peripheral vascular disease, stroke, hypothyroidism and current smoking status. Hypertension (HT) was recorded and graded according to the 2014 SA hypertension guidelines [22]. The body mass index (BMI) was recorded and classified according to the World Health Organization (WHO) classification [23].

Therapy for T2DM (oral, insulin or a combination thereof) was also recorded. The drug therapies that the patients were taking, which could potentially influence the lipid profile, were noted and included beta-blockers, diuretics, corticosteroids, oestrogens and anti-retroviral therapy. The laboratory data included the fasting lipid profile that contained total cholesterol (TC), TG, HDL$\mathrm{C}$, and LDL-C. LDL-C measurement was indirect using the Friedewald equation [18]. If TG exceeded $4.5 \mathrm{mmol} /$ L, LDL-C was not calculated by the laboratory as the equation relies on TG values of $\leq 4.5 \mathrm{mmol} / \mathrm{L}$ [18]. Lipid-lowering therapy type and dosage were also recorded. Information was recorded on a data collection sheet and transferred to a Microsoft Excel spreadsheet for statistical analyses.

\section{Definition of dyslipidaemia}

Optimal lipid targets for T2DM have been defined in the 2018 dyslipidaemia guidelines by the South African Heart Association (SA Heart) and the Lipid and Atherosclerosis Society of Southern Africa (LASSA) [18], as well as the 2017 Society for Endocrinology, Metabolism and Diabetes of South Africa (SEMDSA) guidelines for the management of T2DM [19].

Using these guidelines [18, 19], dyslipidaemia was defined if one or more of the following were present: $\mathrm{TC} \geq$ $4.5 \mathrm{mmol} / \mathrm{L}, \mathrm{TG} \geq 1.7 \mathrm{mmol} / \mathrm{L}, \mathrm{HDL}-\mathrm{C} \leq 1.0 \mathrm{mmol}$ in males, $\leq 1.2 \mathrm{mmol} / \mathrm{L}$ in females, and LDL-C $\geq 1.8 \mathrm{mmol} /$ L. When a single abnormal lipid parameter (TC, TG, HDL-C or LDL-C) was present, it was classified as isolated dyslipidaemia. When two lipid parameters (elevated TG, low HDL-C or elevated LDL-C) were detected, it was classified as combined dyslipidaemia. When all three lipid parameters were abnormal (elevated TG, low HDL-C and elevated LDL-C), it was classified as mixed dyslipidaemia.

\section{Statistical analysis}

Variables were reported according to the distribution of the sample and were not normally distributed. Descriptive statistics namely frequencies and percentages for categorical data and medians with interquartile ranges (IQR) and percentiles for numerical data were calculated. The prevalence of dyslipidaemia was calculated and described using $95 \%$ confidence for the prevalence.

Associations were calculated between gender and lipid abnormalities (LDL-C, HDL-C and TG) using the Kruskal-Wallis test, and between gender and HT using the Chi-squared or Fisher's exact test. A two-sided $p$ value of $<0.05$ was considered to be statistically significant.

\section{Ethical considerations}

Ethics approval was obtained from the Health Sciences Research Ethics Committee (HSREC) of the Faculty of Health Sciences, University of the Free State, before the commencement of the study (UFS-HSD2019/0869/ 2506). Permission to conduct the study was obtained from the Free State Provincial Department of Health and the Head of the Department of Internal Medicine. All methods used in this study were carried out in accordance with relevant guidelines and regulations. The researcher ensured confidentiality by assigning a study number to each file to record clinical data on the datasheet without recording personal information. Because of the retrospective nature of the study, the fact that the information had previously been collected for routine clinical care and no further sample testing nor administration of treatment was conducted, informed consent was waived by the Ethics Committee.

\section{Results}

\section{Overview of the population included in the study}

Figure 1 summarises the total number of patient records screened and the reasons for the inclusion and exclusion 


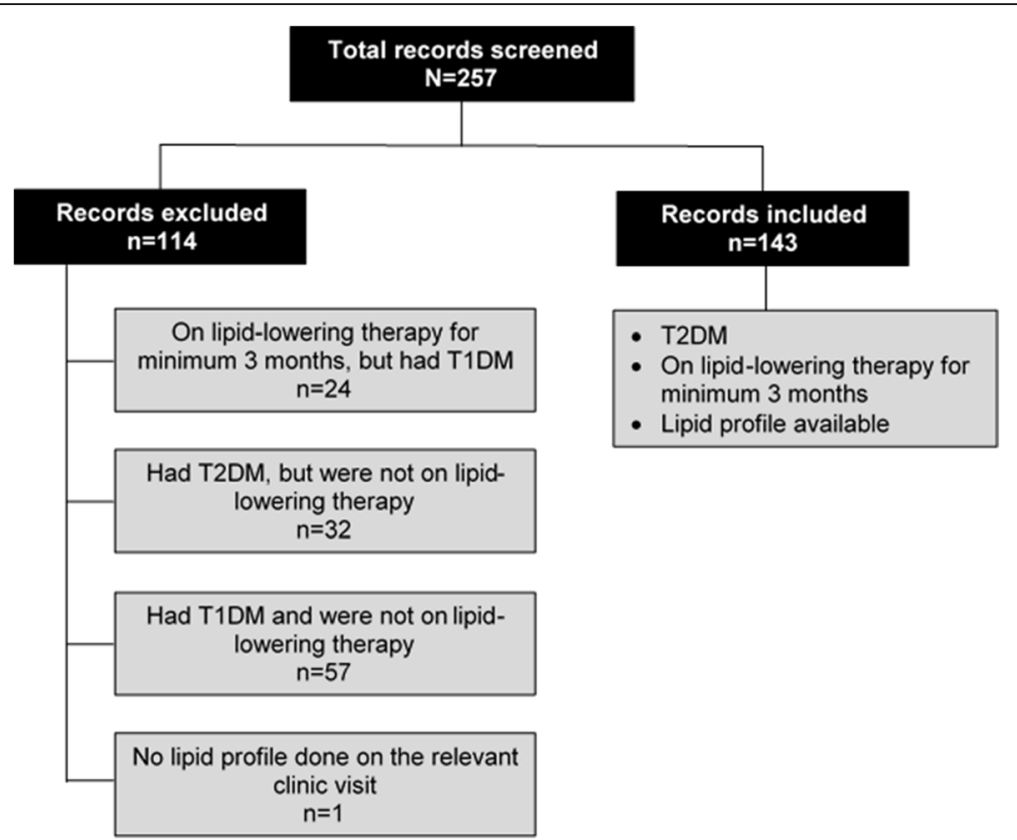

Fig. 1 Strobe diagramme summarising patient records screened and the reasons for the inclusion and exclusion of records

of records. Of the 257 patient records screened over the 3 -month study period, 114 were excluded from the study. The remaining143 participants fulfilled the inclusion criteria. All but two participants $(n=141 ; 98.6 \%)$ were classified as very high-risk as per SA dyslipidaemia guidelines, thus requiring LDL-C of $<1.8 \mathrm{mmol} / \mathrm{L}$ to be on target. The remaining two $(1.4 \%)$ participants' optimal LDL-C target was $<2.5 \mathrm{mmol} / \mathrm{L}$ [18].

\section{Demographic variables}

Most of the participants were aged 40 years or older $(n=133 ; 93 \%)$. The median age of the sample was 63 years (IQR 52-71 years). Most of the participants $(n=92 ; 64.3 \%)$ were female. Slightly more than half of the study participants were of the black ethnic group $(n=74 ; 51.7 \%)$ (Table 1$)$.

\section{Clinical characteristics of the population}

The clinical characteristics of the cohort are summarised in Table 1. The median duration of DM diagnosis was 18 years (IQR range $13-23$ years). Of the 127 study participants whose anthropometric data were available, two thirds $(n=85 ; 66.9 \%)$ were obese with a median BMI of $34.1 \mathrm{~kg} / \mathrm{m}^{2}$ (IQR $28.4-38.9 \mathrm{~kg} / \mathrm{m}^{2}$ ). Female participants had a higher median BMI than male participants (35.6 versus $31.6 \mathrm{~kg} / \mathrm{m}^{2}$; Kruskal-Wallis test, Chi-squared $\left.\left(x^{2}\right)=4.67, p=0.03\right)$. Glycated haemoglobin $(\mathrm{HbA} 1 \mathrm{c})>$ $7 \%$, implying poor control, was noted in 113 (79.0\%) patients, with a median HbA1c of $8.9 \%$ (IQR 7.4$10.1 \%)$. A diagnosis of hypothyroidism was recorded in $21.7 \%(n=31 / 142)$ of participants, with a median thyroid-stimulating hormone (TSH) level of $2.4 \mathrm{mIU} / \mathrm{L}$ (IQR 1.6-3.6 mIU/L), demonstrating good control of hypothyroidism.

Nearly two-thirds of the sample $(n=92 ; 64.3 \%)$ and slightly less than one third $(n=45 ; 31.5 \%)$, respectively, were on a diuretic and beta-blocker therapy (Table 2). Approximately a quarter of the patients $(n=37 ; 25.9 \%)$ were on concomitant diuretic and beta-blocker therapy in keeping with the high rate of hypertension $(n=131$; $91.6 \%$ ) observed among the cohort (Table 1). The prevalence of hypertension in males was similar to that in females (90.2 vs. 92.4\%; Fisher's exact test $p=0.7$ ). Among four patients on human immunodeficiency virus antiretroviral therapy (HIV ART) (Table 2), two were documented to be on efavirenz-based therapy, while in the remaining two, antiretroviral therapy regimen information could not be retrieved from the file records.

\section{Lipid-lowering therapy}

The most common lipid-lowering therapy among the cohort was a statin monotherapy $(n=135 ; 94.4 \%)$, followed by dual statin and fibrate $(n=5 ; 3.5 \%)$ and a fibrate monotherapy $(n=3 ; 2.1 \%)$ (Table 1$)$. No patients were on any other type of lipid-lowering therapy including ezetimibe. The most commonly prescribed statin therapy was simvastatin $(n=128 ; 91.4 \%)$ followed by atorvastatin $(n=12 ; 8.6 \%)$. No patients were on rosuvastatin or any other type of statin. The median dose of simvastatin in 128 participants was $30 \mathrm{mg}$ (IQR 20$40 \mathrm{mg}$ ), while in 12 participants on atorvastatin, the median dose was also $30 \mathrm{mg}$ (IQR 20-40 mg). As shown in 
Table 1 Demographic and clinical information of patients with type 2 diabetes mellitus ( $n=143$, otherwise as indicated)

\begin{tabular}{|c|c|}
\hline Variable & n (\%) \\
\hline \multicolumn{2}{|l|}{ Age } \\
\hline Median in years (IQR) & $63(52-71)$ \\
\hline \multicolumn{2}{|l|}{ Gender } \\
\hline Male & $51(35.7)$ \\
\hline Female & $92(64.3)$ \\
\hline \multicolumn{2}{|l|}{ Ethnicity } \\
\hline Black & $74(51.7)$ \\
\hline Mixed race & $11(7.7)$ \\
\hline White & $58(40.6)$ \\
\hline Ischaemic heart disease & $30(21.0)$ \\
\hline Stroke & $7(4.9)$ \\
\hline Cigarette smoking $(n=113)$ & $12(10.6)$ \\
\hline Peripheral vascular disease & $9(6.3)$ \\
\hline Hypertension & $131(91.6)$ \\
\hline Hypothyroidism & $31(21.7)$ \\
\hline Body mass index $\geq 30 \mathrm{~kg} / \mathrm{m}^{2}(n=127)$ & $85(66.9)$ \\
\hline \multicolumn{2}{|l|}{ Blood pressure } \\
\hline Grade 1 hypertension & $13(9.1)$ \\
\hline Grade 2 hypertension & $8(5.6)$ \\
\hline Grade 3 hypertension & $9(6.3)$ \\
\hline Isolated systolic hypertension & $45(31.5)$ \\
\hline \multicolumn{2}{|l|}{ Antidiabetic therapy } \\
\hline Oral therapy only & $5(3.5)$ \\
\hline Insulin therapy only & $53(37.1)$ \\
\hline Dual oral and insulin therapy & $85(59.4)$ \\
\hline $\mathrm{HbA} 1 c^{\mathrm{a}}>7 \%$ & $113(79.0)$ \\
\hline \multicolumn{2}{|l|}{ Lipid-lowering therapy } \\
\hline Statin only & $135(94.4)$ \\
\hline Fibrate only & $3(2.1)$ \\
\hline Dual statin and fibrate therapy & $5(3.5)$ \\
\hline
\end{tabular}

${ }^{a}$ HbA1c glycated haemoglobin

Table 2 Patient drug therapy list $(n=143)$ that may influence lipid profiles

\begin{tabular}{ll}
\hline Type of agent & $\mathbf{n}(\%)$ \\
\hline Corticosteroids & $2(1.4)$ \\
Diuretics & $94(64.3)$ \\
Oestrogens & $2(1.4)$ \\
Beta-blockers & $45(31.5)$ \\
HIV antiretroviral therapy (ART) & $4(2.8)$ \\
\hline
\end{tabular}

Table 3 Classification of statins by potency of LDL-C lowering $(n=140)$

\begin{tabular}{ll}
\hline Potency & $\mathbf{n ~ ( \% )}$ \\
\hline High-intensity statin & \\
Atorvastatin $40 \mathrm{mg}$ & $6(4.3)$ \\
Simvastatin $80 \mathrm{mg}$ & $1(0.7)$ \\
Moderate-intensity statin & \\
Atorvastatin $10 \mathrm{mg}$ & $2(1.4)$ \\
Atorvastatin $20 \mathrm{mg}$ & $4(2.9)$ \\
Simvastatin $20 \mathrm{mg}$ & $57(40.7)$ \\
Simvastatin $40 \mathrm{mg}$ & $63(45.0)$ \\
Low-intensity statin & \\
Simvastatin $10 \mathrm{mg}$ & $7(5.0)$ \\
\hline
\end{tabular}

Table 3, of the 140 patients on a statin with or without a fibrate, only seven $(5.0 \%)$ were on a high-intensity statin.

\section{Dyslipidaemia pattern and prevalence}

The distribution of the pattern of dyslipidaemia is shown in Table 4. The prevalence of dyslipidaemia among the cohort was $86.7 \%(n=124 / 143)$ (95\% confidence interval for the prevalence [80.2\%; 91.3\%]). The most frequent lipid abnormality was high LDL-C $(n=84 / 143)$ in 54.9 and $60.9 \%$ of the male and female patients, respectively (Fig. 2).

The finding of 84 participants with elevated LDL-C meant that in $58.7 \%$ of the cohort $(70 \%$ of patients with dyslipidaemia and full lipid profile), LDL-C was not on target (Fig. 2). The median lipid profile indices of the cohort are illustrated in Fig. 2 and the comparison between males and females is shown in Table 5. Female patients had a significantly higher median LDL-C $(2.2$ $\mathrm{mmol} / \mathrm{L}$ versus $1.9 \mathrm{mmol} / \mathrm{L}$; Kruskal-Wallis test, $x^{2}=$ 4.38, $p=0.04$ ) (Table 5). The second most common lipid abnormality was both high TG and low HDL-C $(n=67$

Table 4 Distribution of the pattern of dyslipidaemia among the study cohort $(n=143)$

\begin{tabular}{llll}
\hline Lipids outside target & Parameter & $\mathbf{n}(\%)$ & Total \\
\hline No dyslipidaemia & TG/HDL/LDL & $19(13.3)$ & $19(13.3)$ \\
Isolated dyslipidaemia & TG & $7(4.9)$ & $49(34.3)$ \\
& HDL & $12(8.4)$ & \\
& LDL & $30(21.0)$ & \\
Combined dyslipidaemia & TG + LDL & $19(13.3)$ & $51(35.7)$ \\
& TG + HDL & $17(11.9)$ & \\
Mixed dyslipidaemia & TDL + LDL + HDL + LDL & $15(10.5)$ & \\
Unclassified pattern & LDL not calculated & $4(2.8)$ & $4(2.8)$ \\
\hline TG triglycerides, HDL high-density lipoprotein, LDL low-density lipoprotein
\end{tabular}




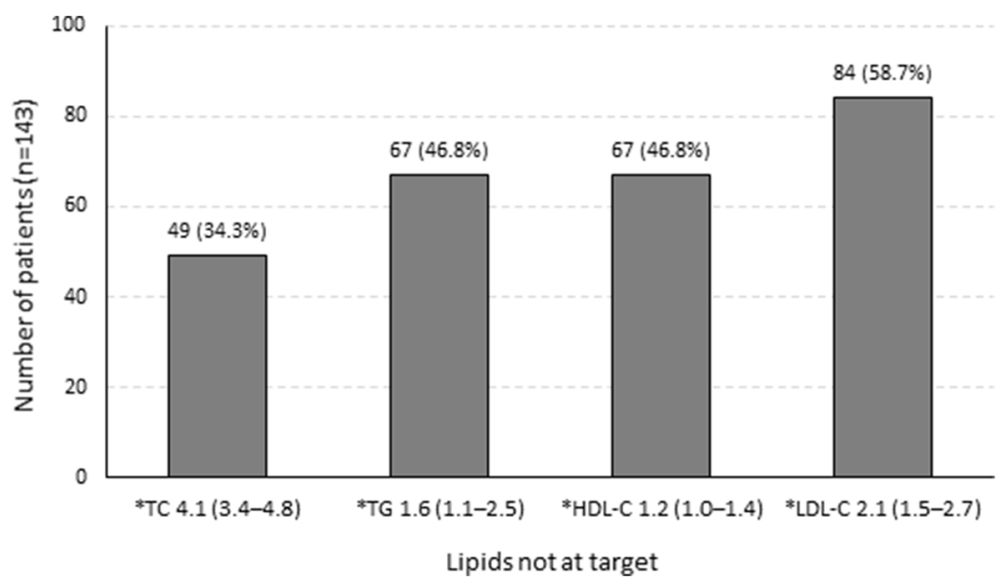

Fig. 2 Individual lipid abnormalities and the median levels of the lipid profile among the study participants $(n=143)$. * Median values in mmol/L with interquartile ranges in brackets. TC: total cholesterol $\geq 4.5 \mathrm{mmol} / \mathrm{L} ; \mathrm{TG}$ : triglycerides $\geq 1.7 \mathrm{mmol} / \mathrm{L} ; \mathrm{HDL}$-C: high-density lipoprotein cholesterol $\geq 1.0 \mathrm{mmol} / \mathrm{L}$ (male) and $\geq 1.2 \mathrm{mmol} / \mathrm{L}$ (female); LDL-C: low-density lipoprotein cholesterol $\geq 1.8 \mathrm{mmol} / \mathrm{L}$

each), affecting $46.8 \%$ of the patient cohort (Fig. 2). For elevated TG, $37.2 \%$ of males and $52.2 \%$ of females contributed to the prevalence with a similar median TG level $(1.5 \mathrm{mmol} / \mathrm{L}$ versus $1.8 \mathrm{mmol} / \mathrm{L}$; Kruskal-Wallis test, $\left.x^{2}=2.30, p=0.1\right)$. In $41.2 \%$ of males and $50.0 \%$ of females, HDL-C was below target, with the median HDL-C significantly lower in males compared to females $(1.1 \mathrm{mmol} / \mathrm{L}$ versus $1.2 \mathrm{mmol} / \mathrm{L}$; Kruskal-Wallis test, $\left.x^{2}=5.44, p=0.02\right)$ (Table 5).

Only 19 (13.3\%) patients in the study (15.7\% of males and $11.9 \%$ of females) had all four lipid parameters at target (Table 4). The most common dyslipidaemia pattern among patients with dyslipidaemia and full lipid indices $(n=51 / 120)$ was combined dyslipidaemia at $42.5 \%$, representing $35.7 \%$ of all the patients in the study (Table 4). It was followed by isolated $(n=49)$ and mixed $(n=20)$ dyslipidaemia patterns at $40.8 \%(34.3 \%$ of the cohort) and $16.7 \%$ (14\% of the cohort), respectively. High LDL-C plus either high TG or low HDL-C was common in males (32.6\% of males), whereas in females, high TG plus either low HDL-C or high LDL-C was most prevalent (29.6\% of females) (Table 6).

In approximately $3 \%$ of the patients $(2.8 \%$ of the total cohort or $3.2 \%$ of patients with dyslipidaemia), the pattern of dyslipidaemia could not be classified (Tables 4 and 6). This was due to LDL-C that had not been calculated because TG was $>4.5 \mathrm{mmol} / \mathrm{L}$, making the Friedewald equation estimation of LDL-C not reliable.

\section{Discussion}

In this study of T2DM patients at high risk for cardiovascular disease, we observed that $58.7 \%$ of the patients were not achieving the LDL-C target of $<1.8 \mathrm{mmol} / \mathrm{L}$ as recommended by SA guidelines. We found a very high prevalence of dyslipidaemia ( $86.7 \%$ in our study) despite the use of lipid-lowering therapy. The most common lipid pattern abnormality among these patients was combined dyslipidaemia attributable largely to TG and LDL$\mathrm{C}$ above target.

Dyslipidaemia prevalence remains high in our study population despite the use of lipid-lowering therapy. Given that hypercholesterolaemia caused 4.4 million deaths as reported in the 2016 Global Burden of Disease study [24], $86.7 \%$ of patients in our study remain at high risk for mortality. Elsewhere in South Africa similar prevalence has been reported, ranging between 87.5 and $93.5 \%$ in T2DM patients $[25,26]$. It is worth noting that even though the two SA studies had been conducted in the public sector, the use of lipid-lowering therapy magnitude was different from our study. In the Naidoo study [26], $83 \%$ of the participants were on any lipid-lowering therapy, and all the patients in the Daya study [25] were only on simvastatin. In our study in comparison, all patients were on lipid-lowering therapy consisting of simvastatin, atorvastatin or bezafibrate. The observation may account for lower dyslipidaemia prevalence in our study. The high prevalence of dyslipidaemia among DM patients on lipid-lowering therapy is not unique to SA and has been observed in international studies with varying prevalence. One large retrospective study in the United Kingdom reported a dyslipidaemia prevalence of $77.1 \%$ in the DM population [27], while in China there was a $70.9 \%$ overall prevalence [28].

Of note is that over half of the patients with T2DM in our study had LDL-C above target and remain at risk of major cardiovascular events despite the use of statin therapy. This finding is similar to an observational study [21] that examined the management of LDL-C levels in 
Table 5 Comparison of the lipid profile of male and female patients

\begin{tabular}{|c|c|c|c|c|}
\hline Lipid component & Total $(n=143)^{\mathrm{a}}$ & Male $(M)(n=51)$ & Female (F) $(n=92)$ & $p$-value \\
\hline $\mathrm{TG} \geq 1.7 \mathrm{mmol} / \mathrm{L}$ & $1.61(1.15-2.49)$ & $1.55(1.08-2.07)$ & $1.84(1.17-2.76)$ & 0.1 \\
\hline \multicolumn{5}{|l|}{$\mathrm{HDL}-\mathrm{C}$} \\
\hline$\leq 1.0 \mathrm{mmol} / \mathrm{L}(\mathrm{M})$ & $1.17(0.97-1.39)$ & $1.09(0.87-1.33)$ & $1.21(1.00-1.43)$ & 0.02 \\
\hline \multicolumn{5}{|l|}{$\leq 1.2 \mathrm{mmol} / \mathrm{L}(\mathrm{F})$} \\
\hline${ }^{\mathrm{a}} \mathrm{LDL}-\mathrm{C} \geq 1.8 \mathrm{mmol} / \mathrm{L}$ & $2.12(1.48-2.67)$ & $1.87(1.27-2.23)$ & $2.22(1.52-2.77)$ & 0.04 \\
\hline
\end{tabular}

SA, reporting that $58.6 \%$ of the patients on lipidlowering therapy did not reach the LDL-C target. Similar to our study, $98.7 \%$ ( $97.9 \%$ in our study) of participants were on statin therapy in this study [21]. In contrast, however, approximately two-thirds of patients in this study $(65.2 \%)$ had DM compared to $100 \%$ in our study and $57.9 \%$ were patients managed in the private sector compared to $100 \%$ in the public sector in our study [21]. When focusing on the under-resourced South African public healthcare setting only, as is the case with our study, two other SA studies have found an even higher proportion of patients not meeting target LDL-C of $<1.8 \mathrm{~mol} / \mathrm{L}$ ranging from 73.5 to $76.5 \%[25,26]$. Of note, in the Daya study, only simvastatin was used by all patients at a mean dose of $20 \mathrm{mg}$ [25], whereas in our study 128 out of 140 patients on statin therapy $(89.5 \%$ of the patients) used simvastatin at the higher median dose of $30 \mathrm{mg}$. The remaining $10.5 \%$ of patients in our study were on fibrates $(2.1 \%)$ and higher potency atorvastatin (8.4\%). The use of the higher median dose of simvastatin and high-potency atorvastatin may account for the higher proportion of patients achieving LDL-C of < $1.8 \mathrm{mmol} / \mathrm{L}$ in our study. In the Naidoo study [26], $83 \%$ of patients with DM (compared to $100 \%$ in our study) were on any lipid-lowering therapy. Again, there was a higher percentage of patients on lipid-lowering therapy in our study and that may explain the higher proportion of patients reaching the target LDL-C compared to the Naidoo study. Nonetheless, over $50 \%$ of patients in our study are still undertreated despite $97.9 \%$ of them being on statin therapy.

Globally, the success rate for LDL-C goal attainment differs from the $41.3 \%$ in our study and has ranged from 39.9 to $61.5 \%$ with the highest success rate among the lowest CV risk groups $[28,29]$. Numerous high-quality studies have proven elevated LDL-C as a cause of ASCV $\mathrm{D}[6,7]$ and the risk of CAD, stroke and heart failure is increased at least four-fold in DM [8]. Patients in our study remain at high risk for adverse $\mathrm{CV}$ events and would benefit from the lowering of LDL-C. The observation of the above target LDL-C and overall high prevalence of dyslipidaemia in our study highlights the lack of optimal management of dyslipidaemia despite the high use of statin therapy.

Although we did not test the reasons behind this poor management of dyslipidaemia in our study, we found that various possibilities are contributing to our findings. We noted in our study that only $5 \%$ of patients receiving statins were on a high-intensity statin. This is surprisingly low given the high dyslipidaemia prevalence and lack of achievement of LDL-C targets. This may be due to clinician inertia and lack of awareness regarding the appropriate use of statin potency and dose titration. Lack of physician awareness of treatment guidelines,

Table 6 Dyslipidaemia pattern among male and female patients with diabetic dyslipidaemia

\begin{tabular}{llll}
\hline Pattern of dyslipidaemia & Male $(\boldsymbol{n = 4 3 )}$ & Female $(\boldsymbol{n = 8 1 )}$ & $\begin{array}{l}\text { Total }(\boldsymbol{n}=\mathbf{1 2 4}) \\
\mathbf{n}(\%)\end{array}$ \\
\hline Isolated & $\mathbf{n}(\%)$ & $\mathbf{n}(\%)$ & $49(39.5)$ \\
High TG & $20(46.5)$ & $4(4.9)$ & $7(5.6)$ \\
Low HDL-C & $3(7.0)$ & $6(7.4)$ & $12(9.7)$ \\
High LDL-C & $6(13.9)$ & $19(23.5)$ & $30(24.2)$ \\
Combined & $11(25.6)$ & $32(39.5)$ & $51(41.1)$ \\
High TG + low HDL-C & $19(44.2)$ & $12(14.8)$ & $17(13.7)$ \\
High TG + high LDL-C & $5(11.6)$ & $12(14.8)$ & $19(15.3)$ \\
Low HDL + high LDL-C & $7(16.3)$ & $8(9.9)$ & $15(12.1)$ \\
Mixed (high TG + low HDL-C+ high LDL-C) & $7(16.3)$ & $17(21.0)$ & $20(16.1)$ \\
Unclassified & $3(7.0)$ & $3(3.7)$ & $4(3.2)$
\end{tabular}

TG triglycerides, HDL high-density lipoprotein cholesterol, LDL-C low-density lipoprotein cholesterol 
underestimation of the patient's CV risk and clinician apathy to titrate statins have been observed before [28]. In SA, the use of high-intensity statin use has ranged from 8.8 to $25.1 \%$, with improved use observed in the private sector clinical practice compared to the public sector $[21,26]$.

Access to high-intensity statins remains a challenge in our low-resource setting. At the time of our study, highintensity statins such as atorvastatin and rosuvastatin were available only on a motivational basis. Additionally, the supply of the high-intensity statins at the primary care level remains inadequate despite successful motivation and approval for use in selected individual patients. Cholesterol absorption inhibitor was not used in any of the patients despite a high prevalence of dyslipidaemia in our study, particularly the LDL-C above target. This is comparable to other local studies with ezetimibe only used in one ( $2.6 \%$ of all participants in that study) out of the three studies of patients with a high prevalence of dyslipidaemia [21, 25, 26]. Ezetimibe was shown to have additional LDL-C lowering when added to statin and improved cardiovascular outcomes [17]. Ezetimibe is accessible only at a tertiary care level on an individual motivated basis. Lack of access is also likely contributing to poor use of high-intensity statin and non-use of ezetimibe in our study despite the poor achievement of LDL$C$ target.

We found a high rate of obesity and this may contribute to the high prevalence of dyslipidaemia, particularly the combined dyslipidaemia pattern that was most prevalent in our study. $66.9 \%$ of patients in our study had $\mathrm{BMI} \geq 30 \mathrm{~kg} / \mathrm{m}^{2}$ and combined dyslipidaemia (mainly high TG plus LDL) was the commonest pattern of dyslipidaemia. Obesity is associated with insulin resistance in T2DM leading to hypertriglyceridaemia, low HDL-C and high LDL-C, particularly sdLDL-C [5].

We also noted in our study that there was poor T2DM control with a median HbA1c of $8.9 \%$ likely contributing to the lipid abnormalities observed. Poor T2DM control has been shown to correlate positively with unfavourable lipid profile [30].

We did not test poor treatment adherence by the patients as a contributor, but lack of adherence is known as a contributor to the underachievement of LDL-C target [28] and may have contributed to our study findings.

Regardless of the reason for patients failing to meet the LDL-C target, it is clear that the residual diabetic dyslipidaemia is associated with high cardiovascular morbidity and mortality [31, 32]. Patients with T2DM would benefit greatly from the appropriate use of lipidlowering therapy, particularly statins [32].

Combined dyslipidaemia was the most common pattern of dyslipidaemia observed, accounting for $42.5 \%$ of patients with dyslipidaemia and full lipid profiles. This is similar to findings observed elsewhere in South Africa. Daya et al. observed that among T2DM patients with dyslipidaemia, $43.8 \%$ had combined dyslipidaemia that was the most common pattern observed [25]. In our study, the combined dyslipidaemia pattern was driven largely by LDL-C and TG levels not at target in $37.2 \%$ of patients with the combined pattern. This likely reflects residual atherogenic diabetic dyslipidaemia that is not fully treated by pharmacological and nonpharmacological interventions. It has been previously documented that overproduction of hepatic TG-rich VLDL and decreased degradation of apolipoprotein $B$ (apoB), a major component of VLDL, in insulin-deficient and/or resistant individuals contribute significantly to hypertriglyceridaemia [5]. Additionally, elevated LDL largely sdLDL, and glycated LDL that participate in atherosclerosis are observed in individuals with T2DM, obesity and insulin resistance. This atherogenic LDL is the hallmark of diabetic dyslipidaemia [5]. Indeed, patients in our study had high rates of obesity (median BMI $34.1 \mathrm{~kg} / \mathrm{m}^{2}$ ) and poorly controlled T2DM (HbA1c > $7 \%$ in $79 \%$ of patients) that could explain the observed dyslipidaemia pattern.

Our study had several limitations that should be noted. As a retrospective study, selection or information bias was inherent and cross-sectional design precluded any temporal association between baseline and subsequent LDL-C levels following lipid-lowering therapy. Dyslipidaemia due to secondary drug causes, such as thiazide diuretics and beta-blockers, could not completely be ruled out as a confounder. We did not collect data on lipid-lowering therapy contraindications, adverse effects or adherence to treatment that might affect the use of lipid-lowering therapy. We also did not collect data on how long the patients were taking lipid-lowering medication for and that could have affected lipid profiles. Because it was conducted in a tertiary diabetes clinic, the study might represent a particular population that is at the highest $\mathrm{CV}$ risk and with difficult to control lipid profiles. As a result, the findings may not be generalisable to the entire South African T2DM population. Further large prospective studies reflecting prevalence in secondary care and district hospitals, as well as primary health care clinics in a public sector setting, are recommended to determine the pattern and prevalence of dyslipidaemia. These studies should also assess the availability, access and use of lipid-lowering therapy among the South African T2DM population.

\section{Conclusions}

Our study draws special attention to the underachievement of lipid targets in patients with T2DM who are already taking lipid-lowering therapy. A high prevalence of dyslipidaemia and the underuse of high-intensity 
statin therapy was observed, despite available clinical guidelines. We highlight the need for better education of both healthcare providers at all levels of care and patients regarding the intensification of lipid-lowering therapy among T2DM whenever appropriate and indicated. Our study also should inform the healthcare policymakers to address the accessibility of the more potent lipid-lowering therapy, such as high potency-statins and additional lipid-lowering therapy like ezetimibe, in the public sector healthcare setting to improve the clinical management of diabetic dyslipidaemia. These measures, along with improved strategies to address poor glycaemic control and modifiable lifestyle factors such as the high rate of obesity and hypertension, could help to reduce excess ASCVD morbidity and mortality associated with residual diabetic dyslipidaemia. A large prospective study in the public sector setting is needed to further evaluate the prevalence and pattern of dyslipidaemia, and the appropriate use and availability of lipidlowering therapy among T2DM patients.

\section{Abbreviations}

apoB: Apolipoprotein B; BMI: Body mass index; CAD: Coronary artery disease; ASCVD: Atherosclerotic cardiovascular disease; CV: Cardiovascular; DM: Diabetes mellitus; HbA1c: Glycated haemoglobin; HDL-C: High-density lipoprotein cholesterol; HT: Hypertension; LDL-C: Low-density lipoprotein cholesterol; SA: South Africa; sdLDL: Small dense low-density lipoprotein cholesterol; T2DM: Type 2 diabetes mellitus; TG: Triglyceride; TSH: Thyroidstimulating hormone; VLDL: Very low-density lipoprotein

\section{Acknowledgements}

Dr. Daleen Struwig, medical writer/editor/ Faculty of Health Sciences, University of the Free State, for technical and editorial preparation of the article.

\section{Authors' contributions}

LP conceptualised, designed and executed the study and was the primary author of the manuscript. LP wrote the manuscript. TRPM assisted with the editing of the article. RN performed the statistical analyses and assisted with the editing of the article. LP, TRPM and RN contributed to the interpretation of data and analyses. All authors read and approved the final manuscript.

\section{Funding}

None.

\section{Availability of data and materials}

The datasets used and/or analysed during the current study are available from the corresponding author on reasonable request.

\section{Declarations}

\section{Ethics approval and consent to participate}

The study was approved by the Health Sciences Research Ethics Committee (HSREC) of the University of the Free State with ethical clearance number UFS-HSD2019/0869/2506. Permission to use hospital data was granted by the Department of Health, Free State Province, South Africa.

\section{Consent for publication}

Due to the retrospective nature of the study, the requirement to obtain informed consent was waived by the Health Sciences Research Ethics Committee.

\section{Competing interests}

The authors declare that they have no competing interests.

\section{Author details}

'Division of Endocrinology, Department of Internal Medicine, Faculty of Health Sciences, University of the Free State, Universitas Academic Hospital, Bloemfontein, South Africa. ${ }^{2}$ Department of Internal Medicine, Faculty of Health Sciences, University of the Free State, 205 Nelson Mandela Drive, 9300 Bloemfontein, South Africa. ${ }^{3}$ Department of Internal Medicine, Faculty of Health Sciences, University of the Free State, Universitas Academic Hospital, Bloemfontein, South Africa. ${ }^{4}$ Department of Biostatistics, Faculty of Health Sciences, University of the Free State, Bloemfontein, South Africa.

Received: 15 April 2021 Accepted: 8 July 2021

Published online: 08 August 2021

\section{References}

1. International Diabetes Federation. IDF Diabetes Atlas. 9th ed. Brussels: International Diabetes Federation; 2019. Available at: http://www.idf.org/a boutdiabetes/what-is-diabetes/facts-figures.html

2. Blom DJ. Dyslipidaemia in type 2 diabetes: review. S Afr J Diabetes Vasc Dis. 2013;10(2):48-50. Available at: http://www.diabetesjournal.co.za/onlinejourna l/vol10/vol10 issue2/files/assets/basic-html/index.htm.

3. Athyros VG, Doumas M, Imprialos KP, Stavropoulos K, Georgianou E, Katsimardou A, et al. Diabetes and lipid metabolism. Hormones (Athens). 2018;17(1):61-7. https://doi.org/10.1007/s42000-018-0014-8

4. Mach F, Baigent C, Catapano AL, Koskinas KC, Casula M, Badimon L, et al. 2019 ESC/EAS Guidelines for the management of dyslipidaemias: lipid modification to reduce cardiovascular risk. Eur Heart J. 2020;41(1):111-88. https://doi.org/10.1093/eurheartj/ehz455

5. Schofield JD, Liu Y, Rao-Balakrishna P, Malik RA, Soran H. Diabetes dyslipidemia. Diabetes Ther. 2016;7(2):203-19. https://doi.org/10.1007/s133 00-016-0167-x

6. Ference BA, Ginsberg HN, Graham I, Ray KK, Packard CJ, Bruckert E, et al Low-density lipoproteins cause atherosclerotic cardiovascular disease. 1. Evidence from genetic, epidemiologic, and clinical studies. A consensus statement from the European Atherosclerosis Society Consensus Panel. Eur Heart J. 2017;38(32):2459-72. https://doi.org/10.1093/eurheartj/ehx144

7. Michos ED, McEvoy JW, Blumenthal RS. Lipid management for the prevention of atherosclerotic cardiovascular disease. N Engl J Med. 2019; 381(16):1557-67. https://doi.org/10.1056/NEJMra1806939

8. Martín-Timón I, Sevillano-Collantes C, Segura-Galindo A, Del Cañizo-Gómez FJ. Type 2 diabetes and cardiovascular disease: have all risk factors the same strength? World J Diabetes. 2014;5(4):444-70. https://doi.org/10.4239/wjd.v5. i4.444

9. Kamil S, Sehested TSG, Carlson N, Houlind K, Lassen JF, Bang CN, et al. Diabetes and risk of peripheral artery disease in patients undergoing firsttime coronary angiography between 2000 and 2012 - a nationwide study. BMC Cardiovasc Disord. 2019;19(1):234. https://doi.org/10.1186/s12872-01 9-1213-1

10. Dunlay SM, Givertz MM, Aguilar D, Allen LA, Chan M, Desai AS, et al. Type 2 diabetes mellitus and heart failure, a scientific statement from the American Heart Association and Heart Failure Society of America. J Card Fail. 2019; 25(8):584-619. https://doi.org/10.1016/j.cardfail.2019.05.007

11. Kenny HC, Abel ED. Heart failure in type 2 diabetes mellitus: impact of glucose-lowering agents, heart failure therapies, and novel therapeutic strategies. Circ Res. 2019;124(1):121-41. https://doi.org/10.1161/CIRCRESA HA.118.311371

12. Koskinas KC, Siontis GCM, Piccolo R, Mavridis D, Räber L, Mach F, et al. Effect of statins and non-statin LDL-lowering medications on cardiovascular outcomes in secondary prevention: a meta-analysis of randomized trials. Eur Heart J. 2018;39(14):1172-80. https://doi.org/10.1093/eurheartj/ehx566

13. Collins R, Reith C, Emberson J, Armitage J, Baigent C, Blackwell L, et al. Interpretation of the evidence for the efficacy and safety of statin therapy. Lancet. 2016;388(10059):2532-61. https://doi.org/10.1016/S01406736(16)31357-5

14. Naeem F, McKay G, Fisher M. Cardiovascular outcomes trials with statins in diabetes. Br J Diabetes. 2018;18(1):7-13. https://doi.org/10.15277/bjd.2 018.161

15. Chou R, Dana T, Blazina I, Daeges M, Jeanne TL. Statins for prevention of cardiovascular disease in adults: evidence report and systematic review for the US Preventive Services Task Force. JAMA. 2016;316(19):2008-24. https:// doi.org/10.1001/jama.2015.15629 
16. Arnett DK, Blumenthal RS, Albert MA, Buroker AB, Goldberger ZD, Hahn EJ et al. 2019 ACC/AHA guideline on the primary prevention of cardiovascular disease: a report of the American College of Cardiology/American Heart Association Task Force on Clinical Practice Guidelines. Circulation. 2019; 140(11):e596-e646. https://doi.org/10.1161/CIR.0000000000000678

17. Cannon CP, Blazing MA, Giugliano RP, McCagg A, Wijte JA, Theroux P, et al. Ezetimibe added to statin therapy after acute coronary syndromes. N Engl J Med. 2015;372(25):2387-97. https://doi.org/10.1056/NEJMoa1410489

18. Klug E, Raal FJ, Marais AD, Smuts CM, Schamroth C, Jankelow D, et al. South African dyslipidaemia guideline consensus statement: 2018 update. A joint statement from the South African Heart Association (SA Heart) and the Lipid and Atherosclerosis Society of Southern Africa (LASSA). S Afr Med J. 2018;108(11b):973-1000. Available at: http://www.samj.org.za/index.php/sa mj/article/view/12479/8686

19. Amod A. SEMDSA 2017 guidelines for the management of type 2 diabetes mellitus. J Eendocinol Metab Diabetes S Afr. 2017;22(1 Suppl 1):S1-196. Available at: http://www.jemdsa.co.za/index.php/JEMDSA/article/view/647

20. Halcox JP, Banegas JR, Roy C, Dallongeville J, De Backer G, Guallar E, et al. Prevalence and treatment of atherogenic dyslipidemia in the primary prevention of cardiovascular disease in Europe: EURIKA, a cross-sectional observational study. BMC Cardiovasc Disord. 2017;17(1):160. https://doi.org/1 0.1186/s12872-017-0591-5

21. Blom DJ, Raal F, Amod A, Naidoo P, Lai Y. Management of low-density lipoprotein cholesterol levels in South Africa: the International ChoLesterol management Practice Study (ICLPS). Cardiovasc J Afr. 2019;30(1):15-23. https://doi.org/10.5830/CVJA-2018-054

22. Seedat YK, Rayner BL, Veriava Y. South African hypertension practice guideline 2014. Cardiovasc J Afr. 2014;25(6):288-94. https://doi.org/10.5830/ CVJA-2014-062

23. World Health Organization. Obesity: preventing and managing the global epidemic: report of a WHO consultation. Geneva: WHO; 2000. Available at: https://apps.who.int/iris/handle/10665/42330

24. Noubiap JJ, Bigna JJ, Nansseu JR, Nyaga UF, Balti EV, Echouffo-Tcheugui JB, et al. Prevalence of dyslipidaemia among adults in Africa: a systematic review and meta-analysis. Lancet Glob Health. 2018;6(9):e998-e1007. https:// doi.org/10.1016/S2214-109X(18)30275-4

25. Daya R, Bayat Z, Raal F. Prevalence and pattern of dyslipidaemia in type 2 diabetes mellitus patients at a tertiary care hospital. J Endocrinol Metab Diabetes S Afr. 2017;22(3):31-5. Available at: https://www.tandfonline.com/ doi/full/10.1080/16089677.2017.1360064\#.VQcjlpWJhgU

26. Naidoo S, Raal F. Pattern of dyslipidaemia in relation to statin use in patients with type 2 diabetes mellitus attending a tertiary care hospital. J Endocrinol Metab Diabetes S Afr. 2020;25(1):6-11. Available at: https://www. tandfonline.com/doi/full/10.1080/16089677.2019.1686869

27. Jameson K, Amber V, D'Oca K, Mills D, Giles A, Ambegaonkar B. Impact of lipid-lowering therapy on the prevalence of dyslipidaemia in patients at high-risk of cardiovascular events in UK primary care - a retrospective database study. Int J Clin Pract. 2013;67(12):1228-37. https://doi.org/10.1111/ ijcp.12238

28. Zhao S, Wang Y, Mu Y, Yu B, Ye P, Yan X, et al. Prevalence of dyslipidaemia in patients treated with lipid-lowering agents in China: results of the DYSlipidemia International Study (DYSIS). Atherosclerosis. 2014;235(2):463-9. https://doi.org/10.1016/j.atherosclerosis.2014.05.916

29. Danchin N, Almahmeed W, Al-Rasadi K, Azuri J, Berrah A, Cuneo CA, et al. Achievement of low-density lipoprotein cholesterol goals in 18 countries outside Western Europe: the International ChoLesterol management Practice Study (ICLPS). Eur J Prev Cardiol. 2018;25(10):1087-94. https://doi. org/10.1177/2047487318777079

30. Mahajan R, Koley S. Association of HbA1c with Lipid profiles in patients with type 2 diabetes mellitus. Int J Biomed Res. 2016;7(3):139-43. Available at: https://ssjournals.com/index.php/ijbr/article/view/3098

31. Warraich HJ, Rana JS. Dyslipidemia in diabetes mellitus and cardiovascular disease. Cardiovasc Endocrinol. 2017;6(1):27-32. https://doi.org/10.1097/XCE. 0000000000000120

32. Jialal I, Singh G. Management of diabetic dyslipidemia: an update. World J Diabetes. 2019;10(5):280-90. https://doi.org/10.4239/wjd.v10.15.280

\section{Publisher's Note}

Springer Nature remains neutral with regard to jurisdictional claims in published maps and institutional affiliations.

\section{Ready to submit your research? Choose BMC and benefit from}

- fast, convenient online submission

- thorough peer review by experienced researchers in your field

- rapid publication on acceptance

- support for research data, including large and complex data types

- gold Open Access which fosters wider collaboration and increased citations

- maximum visibility for your research: over $100 \mathrm{M}$ website views per year

At BMC, research is always in progress.

Learn more biomedcentral.com/submissions 